\title{
Preservation of fresh fruits, vegetables and quality standards during storage utilizing energy-efficient technologies for improved livelihoods.
}

\author{
Erick K Ronoh*, Jomo Kenyatta \\ University of Agriculture and Technology, Kenya
}

\begin{abstract}
Food and energy security are two key global challenges. In Kenya, agriculture is mainly characterized by dominance of primary production with little post-production interventions such as preservation. Preservation of fruits and vegetables can provide rural households with better diets year round and incomes. Therefore, the study focused on developing energy efficient cooling technology utilizing renewable energy for preservation of fresh fruits and vegetables.

Through a renewable energy for food processing (christened RE4 Food) project; an evaporative charcoal cooler was purposely developed for use by a registered farmer group in Kirinyaga County, Kenya. The developed cooler measured $4 \mathrm{~m}$ long, $4 \mathrm{~m}$ wide and $2.5 \mathrm{~m}$ high with a storage capacity of $40 \mathrm{~m} 3$. Preliminary results indicate promising results in terms of microclimate conditions (temperature and relative humidity), shelf-life and quality of the produce. The charcoal cooler should be optimized to ensure a favorable microclimate and controlled wetting of charcoal walls thus saving water for other agricultural activities. To improve capacity among farmers, training of beneficiaries was conducted focusing on operation and maintenance of the facility, quality standards, packaging, business aspects and book keeping, group dynamics and marketing. To ensure sustainable and maximum returns from the facility, farmers were also trained on the development of health foods for subsistence as well as for export.

Further, the farmer group was linked with renowned fresh produce exporters in order to maintain required quality standards along the entire value chain of fruits and vegetables. Through established marketing linkages, farmers can package their value added products and deliver them to ready markets, thus generating incomes to the rural poor. These linkages provide valuable business opportunities badly needed in rural communities. Overall, the interventions undertaken by this study are vital in minimization of postharvest losses, enhancing food security and realizing nutrition sensitive agriculture in Kenya and beyond.
\end{abstract}

Keywords: Food preservation, Techniques in Food preservation, Freezing, Canning, Food safety

\section{Introduction}

Food preservation prevents the expansion of microorganisms (such as yeasts), or alternative microorganisms (although some strategies work by introducing benign bacterium or fungi to the food), similarly as swiftness the reaction of fats that cause rancidity. Food preservation can also embrace processes that inhibit visual deterioration, like the accelerator browning reaction in apples when they're cut throughout food preparation.

Many processes designed to preserve food involve over one food preservation methodology. Protective fruit by turning it into jam, as an example, involves boiling (to scale back the fruit's wet content and to kill bacterium, etc.), sugaring (to forestall their re-growth) and waterproofing among an airtight jar (to forestall recontamination). Some ancient strategies of protective food are shown to own a lower energy input and carbon footprint, when put next to fashionable strategies

Freezing, drying, pickling, and canning are all nice ways that to preserve the vegetables, fruits and herbs.

Fruits and vegetables are plant derived merchandise which may be consumed in its raw type while not undergoing process or conversion. Fresh Fruits and Vegetables (FFV) are merchandise that are cleansed, peeled, sliced, cubed or ready for convenience or ready-to-eat consumption however remains in a very living 14th International Conference on Agriculture \& Horticulture and breathing state. strategies of protective FFV to retain its quality includes laundry with salt, oxide, organic acids, heat water and gas for cleansing and sanitization; use of antimicrobial edible films and coatings; and controlled atmosphere storage and changed atmosphere packaging of fruits and vegetables.

To prepare recent vegetables for protective, perpetually wash in many running water, take away non-edible elements like stems and seeds, peel or trim as desired, and take slices or cubes.

Here are many vegetable protective strategies, from the simplest (and least expensive) to the foremost difficult.

Refrigerator pickles are the best approach you'll be able to preserve recent vegetables and extend their period of time for a couple of days. Consider them as a sort of dish, or just crisp, mouthwatering sustenance. These straightforward icebox pickle recipes use many kinds of vegetables and even some fruits.

Salting is a simple and old school methodology for protective vegetables like preserved cauliflower. Seasoning was promoted within the early twentieth century as an alternate to canning. Many of us at home with the technique contemplate preserved vegetables to be way superior in style and texture than canned or frozen ones. You need to store preserved vegetables in a very icebox $\left(<40^{\circ} \mathrm{F}\right)$ or cold cellar wherever temperatures ne'er go on top of $50^{\circ} \mathrm{F}$. Before victimisation preserved vegetables, you 
always take away excess salt by soaking in cold water for two to eight hours. you'll be able to prepare and serve preserved vegetables within the same ways that you'd as if they were recent, cold in salads, simmered in soups, or ready as a hot vegetable dish.

Fermenting with salt uses low salt concentration $\left(2 \frac{1}{2} \%\right.$ to five weight of the salt per weight of the food), to market fermentation. Dish and kimchi are maybe the foremost well-known examples.

However the techniques are often applied to nearly any vegetable. This formula for bitter turnips is acknowledged in jap Europe as kisla repa or sauerruben.

Drying vegetables is simple to try and do in your standard gas or electrical kitchen appliance. Electrical food dehydrator appliances provide additional management than your kitchen appliance. you'll be able to purchase a basic model for as very little as $\$ 50$. One in all the most effective ways that to use dried vegetables is that this versatile formula for bean and food soup.

Freezing vegetables for future storage needs adequate packaging and a zealous deep-freeze appliance (known as a deep freeze) to relax foods to a minimum of $0^{\circ} \mathrm{F}$. True temperature reduction isn't attainable within the \{freezer|deep-freeze|Deepfreeze|deep freezer|electric icebox|fridge\} compartment of your refrigerator wherever the temperature generally hovers close to $32^{\circ} \mathrm{F}$. Treat your refrigerator-freezer sort of a bank account. Use it for brief term temperature reduction of food that you just attempt to use among one month. To use temperature reduction as a good food preservation methodology, habitually clean out your deepfreeze by intense the food.

Canning needs a modest investment in instrumentality and skills that are straightforward to be told and apply. The elemental tasks embrace selecting the proper canning methodology, taking precautions to forestall gastrointestinal disorder poisoning, and making ready and process canned foods properly. There are 2 canning methods: Boiling Water-Bath (BWB) canning and steam-pressure canning. That methodology you utilize depends on whether or not the food you intend to will is high acid or low acid. High-acid foods embrace most fruits and fruit merchandise. additionally, low acid vegetables are often canned victimisation tested recipes for pickles, relish, and tomato merchandise, that contain accessorial acid, typically vinegar.

\section{Conclusion}

Food preservation is a very important step after harvesting and before its marketing. The produce needs to be fresh and look safe \& hygiene for consumptions. our research work is focused on developing energy efficient cooling technology utilizing renewable energy for preservation of fresh fruits and vegetables.

\section{Biography}

Erick K Ronoh is a Lecturer in the Department of Agricultural and Biosystems Engineering, School of Biosystems and Environmental Engineering, Jomo Kenyatta University of Agriculture and Technology (JKUAT), Kenya. He has obtained his PhD in Horticultural Sciences (Dr. rer. hort.) in June 2016 at the Leibniz Universität Hannover, Germany. He also holds an MSc in Agricultural Processing Engineering and a BSc in Agricultural Engineering, both from JKUAT. In addition to his teaching career, he has been actively involved in a number of research projects in the fields of Agricultural Processing Engineering, Agricultural Structures, Renewable Energy and value addition for enhanced food and nutrition security as well improved rural livelihoods.

His vision is to be a reliable, dependable and result oriented professional by advancing knowledge in the field of agricultural processing engineering aimed at mitigating food insecurity, alleviating poverty and enhancing management of available natural resources.

\section{References}

1. Basediya A L, Samuel DVK and Beera V, et al. Evaporative cooling system for storage of fruits and vegetables - a review. Journal of Food Science and Technology 2013;50(3):429-442.

2. Camargo J R. Evaporative cooling: Water for thermal comfort. Ambiente e Agua - An Interdisciplinary Journal of Applied Science 2007;3:51-61.

3. Hodges R J, Buzby J C and Bennett B, et al. Postharvest losses and waste in developed and less developed countries: Opportunities to improve resource use. Journal of Agricultural Science 2010;149:37-45.

4. Zahra G and John AB. A passive evaporative cooling system by natural ventilation. Build Environment 1996;31(6):503-507.

\section{*Correspondence to:}

Erick K Ronoh

University of Agriculture and Technology

Kenya

E-mail: ronoh@jkuat.ac.ke 